Acta Theriologica 41 (1): 51-58, 1996.

PL ISSN 0001-7051

\title{
Reproductive strategies of the raccoon dog and the red fox in Finland
}

\author{
Kaarina KAUHALA
}

\begin{abstract}
Kauhala K. 1996. Reproductive strategies of the raccoon dog and the red fox in Finland. Acta Theriologica 41: 51-58.

Reproductive strategies of the raccoon dog Nyctereutes procyonoides (Gray, 1834) and the red fox Vulpes vulpes (Linnaeus, 1758) were studied in southern Finland in 1986-1995. Litter size and relative litter weight, body size, population status and ecology were compared. Although the body size is almost equal, diet rather similar and both raccoon dog and fox populations have been rather stable during the study period, the litter sizes and relative litter weights differ greatly. The mean litter size of the raccoon dog was 9.0 and that of the red fox 5.1. The mean relative litter weight was $18.3-24.0 \%$ for the raccoon dog and $10.4-12.5 \%$ for the red fox. Thus, raccoon dog females are able to invest relatively more in reproduction than the red fox. There are several features in the ecology and behaviour of these species which can explain the different strategies. First, vole cycles have a strong effect on red fox reproduction, but have only a week effect on the litter size of the raccoon dog. Second, the raccoon dog sleeps during harsh winters and females are in good condition in the breeding season regardless of the weather and food supply during the winter. The red fox is always active in winter when food availability may be low and moving in snow is energetically costly. Omnivory, the ability to accumulate large fat reserves and winter dormancy guarantee the good condition of raccoon dog females even in fluctuating environments by reducing the relative costs of reproduction. Third, raccoon dog pups are easy prey to other predators, and mortality during their first year is very high. If mortality rate before the reproductive age is high and independent of litter size, natural selection will favour large litters. Juvenile mortality among red foxes is lower, and it probably would increase in larger litters due to eg starvation.
\end{abstract}

Finnish Game and Fisheries Research Institute, P. O. Box 202, FIN-00151 Helsinki, Finland

Key words: Nyctereutes procyonoides, Vulpes vulpes, reproductive strategy, Finland

\section{Introduction}

Life history traits usually correlate with body weight and with each other (see eg Western 1979, Eisenberg 1981). For instance, a small mammal usually has large litters with relatively heavy new born. A large mammal probably has small litters, and the weight of the new born is low relative to the mother's weight (Eisenberg 1981). The negative relationship between litter size and body weight concerns mammals weighing more than $1 \mathrm{~kg}$ (Tuomi 1980).

If life history traits do not correlate with body weight, the reasons should be found in the species ecology (especially diet and feeding ecology) and/or the status 
of the population, ie whether the population is increasing, stable or declining (Western 1979).

In some respects canids are exceptions among mammals. The basic mating system among canids is monogamy, which is unusual (Kleiman 1977). While the litter size generally decreases with increasing body weight, among canids the litter size either does not correlate with body weight (Bekoff et al. 1981, Kauhala 1992), or it increases with increasing body weight (Moehlman 1986).

Diet, especially prey size, may affect the hunting strategy and social behaviour of canids. Diet and hunting strategy, in turn, seem to be related to litter size. For instance, among large canids, the African hunting dog Lycaon pictus preys on antilopes, hunts in packs and rears the young cooperatively, and has very large litters (Frame et al. 1979, Moehlman 1986). The maned wolf Chrysocyon brachyurus feeds on small food items, forages alone and has small litters (eg Dietz 1984).

The aim of the present paper is to compare the reproductive strategies of two canids, the raccoon dog Nyctereutes procyonoides (Gray, 1834) and the red fox Vulpes vulpes (Linnaeus, 1758). This paper is a synthesis partly based on previously published data, but new data has also been added (see Material and methods). When data of the red fox is lacking from Finland, I refer to literature.

\section{Material and methods}

Weight, length and litter size of the raccoon dog and red fox were determined from carcass material collected from hunters in southern Finland. The hunting season for both species in Finland is from the beginning of August to the end of April. Part of the data (data for 1986-1990) for raccoon dog reproduction have been published earlier (Helle and Kauhala 1995). To determine the mean body size, adult (at least one year old) raccoon dogs and red foxes were examined. Part of these data (data for raccoon dogs from 1986-1990) have also been published (Kauhala 1993), but new data were added (data for 1991-1995). Red fox carcasses were collected in 1989-1995. The carcasses were weighed to within $20 \mathrm{~g}$ and measured from the tip of the nose to the anus to within $0.5 \mathrm{~cm}$.

Altogether 350 raccoon dog and 50 red fox uteri with placental scars or embryos/foetuses were examined. The number of placental scars was counted if the animal was killed in autumn, and the number of embryos (for embryonic litter size) or foetuses (from the latter half of pregnancy, for litter size at birth) was counted, and the foetuses were weighed, if the animal was killed in spring (for details, see Helle and Kauhala 1995). Age determination was done either from the ossification stage of the long bones (radius and ulna) or by sectioning canine teeth and counting annual incremental lines (for details, see Kauhala and Helle 1990). Data of the diet and population status is based on previosly published studies (diet: Lampio 1953, Kauhala et al. 1993a; population status: Helle et al. 1994, Kauhala and Helle 1993, 1995).

\section{Results and discussion}

\section{Litter size and reproductive investment}

The mean litter size of the raccoon dog was 9.0 and that of the red fox 5.1 (Table 1). Other studies on the red fox give mean litter sizes from 3.4 in Sweden 
Table 1. Litter sizes of the raccoon dog and red fox in southern Finland, based on carcass material. Litter size in autumn material is determined by counting placental scars, in spring by counting the number of embryos/foetuses. (Foetus means here a measurable foetus from the latter half of the pregnancy.)

\begin{tabular}{lccccc}
\hline & \multicolumn{2}{c}{ Embryonic litter size } & & \multicolumn{2}{c}{ Litter size at birth } \\
\cline { 5 - 6 } & Autumn & Spring & & Autumn & Spring \\
\hline Raccoon dog & & & & \\
Mean & 9.6 & 9.6 & & 9.0 & 9.0 \\
SD & 2.5 & 2.7 & & 2.4 & 2.8 \\
$n$ & 222 & 128 & & 222 & 77 \\
Red fox & & & & \\
Mean & 5.4 & 5.8 & & 5.2 & 5.1 \\
SD & 1.5 & 1.1 & & 1.3 & 1.6 \\
$n$ & 31 & 16 & & 31 & 15 \\
\hline
\end{tabular}

Table 2. Mean weight and length of raccoon dog foetuses approaching the time of birth from southern Finland. The table gives also the date when the 3 females were killed.

\begin{tabular}{rccc}
\hline Date & $n$ & Mean weight $(\mathrm{g})$ & Mean length $(\mathrm{cm})$ \\
\hline 8.5. & 7 & 139.4 & 16.0 \\
13.5. & 8 & 122.0 & 12.5 \\
14.5. & 7 & 104.6 & 11.9 \\
Mean & & 122.0 & 13.5 \\
\hline
\end{tabular}

in years when voles are scarce (Lindström 1988) to 7.0 in Illinois (Storm et al. 1976).

The mean weight of new born raccoon dogs was $125 \mathrm{~g}$ in a litter of 12 . The female was raised in a fur farm, but I was also able to weigh foetuses of wild caught females. The mean weight of foetuses in May (most raccoon dogs give birth in May in southern Finland, see Helle and Kauhala 1995) was $122 \mathrm{~g}$ ( $\max 153.4 \mathrm{~g}$ ) (Table 2). The weight of new born red foxes is 100-120 g (Lloyd 1980, Macdonald 1987). The gestation period of the raccoon dog is longer (60-62 days) than that of the red fox (53 days, eg Lloyd 1980). This fits to the theory of Bekoff et al. (1984) that omnivorous canids have heavier young and longer gestation period than more carnivorous species.

On the basis of these data one can estimate that the mean weight of raccoon dog litters varies from about 950 to $1250 \mathrm{~g}$, and that of the red fox from 510 to $612 \mathrm{~g}$. Consequently, the mean litter weight relative to female weight in raccoon dogs was $18.3-24.0 \%$, the figure being $10.4-12.5 \%$ for the red fox. 
These figures indicate that raccoon dog females invest relatively more in reproduction than the red fox. Hence, one would expect the costs of reproduction to be so heavy for the raccoon dog female that eg the life span would be much shorter and/or future reproduction success much lower than those of the red fox. However, this does not seem to be the case. Both raccoon dogs and red foxes are able to reproduce at the age of one year, and they can have a litter each year. Productivity of raccoon dog females increases until the age of 5 years and decreases only after that (Helle and Kauhala 1995). The maximum life span of raccoon dogs is around 7-8 years in the wild (Helle and Kauhala 1993). According to Macdonald (1987) only $5 \%$ of foxes reach the age of 4 years and Lloyd et al. (1976) give an annual mortality rate of $64 \%$ for foxes ( $60 \%$ for adult individuals). According to Lindström (1989) the maximum life span of red foxes in Sweden is 7-8 years, and according to Storm et al. (1976) it is around 6 years.

\section{Body size and sexual dimorphism}

The body weight of the raccoon dog and red fox was almost equal, except in late autumn because the raccoon dog sleeps in winter and roughly doubles its weight between early June and November (Kauhala 1993). However, adult females of both species weigh from 4 to $6 \mathrm{~kg}$ in spring and early summer (Table 3 ).

Mean body length of adult raccoon dogs was a little less than that of red foxes (Table 3). Raccoon dogs did not show sexual dimorphism, which can be linked to the monogamy of the species (eg Kauhala et al. 1993b). Red fox males were a little bigger than females, and male/female ratio was 1.06 (see also Lloyd 1980). The sexual dimorphism of the red fox may be connected with the fact that the red fox has a tendency to polygyny (for polygyny and sexual dimorphism, see eg Clutton-Brock et al. 1982). Because the body weight of these canids is almost equal, the different reproductive strategies are not explained by different body weight.

Table 3 . Mean body weight in early summer and length (from the tip of the nose to the anus) of adult raccoon dogs and red foxes in southern Finland.

\begin{tabular}{llll}
\hline \multicolumn{4}{l}{ Body weight } \\
\hline $\begin{array}{l}\text { Raccoon dog } \\
\text { Red fox }\end{array}$ & $5.2 \mathrm{~kg} \quad(\mathrm{SD}=0.9, n=441)$ & females \\
& $4.9 \mathrm{~kg} \quad(\mathrm{SD}=1.1, n=36)$ & females \\
\hline & Body length: & \\
\hline Raccoon dog & $59.8 \mathrm{~cm} \quad(\mathrm{SD}=3.4, n=730)$ & females \\
& $59.8 \mathrm{~cm}$ & $(\mathrm{SD}=5.6, n=292)$ & males \\
Red fox & $66.8 \mathrm{~cm}$ & $(\mathrm{SD}=2.7, n=121)$ & females \\
& $70.5 \mathrm{~cm}$ & $(\mathrm{SD}=3.8, n=40)$ & males \\
\hline
\end{tabular}




\section{Population status}

The raccoon dog originates in the Far East and it was introduced to Europe mainly in the first half of this century (Lavrov 1971). In Finland the population peaked in the mid-1980s and has since then been regulated density dependently (Kauhala and Helle 1993, 1995). Thus, the rapid increase phase in Finland was before the mid-1980s. This study began in 1986 and has been carried out during a more or less stable phase, not during the increase phase after introduction.

The red fox is a native carnivore in Europe. In Finland the population has been rather stable during the study period in the late 1980s and early 1990s (Helle et al. 1994). Because the populations of both species have been quite stable in Finland during the study period, the difference in the reproductive strategies cannot be explained by different population status.

\section{Diet and feeding ecology}

In Finland, the raccoon dog and red fox live in rather similar habitats, mainly in boreal coniferous forest, but both may also come near human settlements visiting compost heaps and foraging on fields, too. Both are omnivorous and solitary hunters feeding on small mammals, berries and fruits, invertebrates, birds, carrion, frogs, etc. (Table 4). The raccoon dog feeds, however, more frequently on shrews, invertebrates, carrion and plants than the red fox. The raccoon dog is extremely omnivorous also in the original distribution area in the Far East (Judin 1977).

Table 4. Diet of the raccoon dog and the red fox in Finland based on stomach analysis. The figures give the frequency of occurrence (\%) of different food items in stomachs. The table is based on previously published studies; raccoon dog: Kauhala et al. 1993a, red fox: Lampio 1953. Both studies include stomachs mainly from the hunting season (August-April). * included in carcasses.

\begin{tabular}{lcc}
\hline & $\begin{array}{c}\text { Raccoon dog } \\
n=172\end{array}$ & $\begin{array}{c}\text { Red fox } \\
n=325\end{array}$ \\
\hline Small rodents & 40.0 & 45.7 \\
Shrews & 26.0 & - \\
Hares & 8.0 & 7.7 \\
Grouses & 10.0 & 12.1 \\
Waterfowl & 2.0 & 1.7 \\
Chicken & $*$ & 14.5 \\
Passerines & 13.0 & 6.5 \\
Lizards and frogs & 8.0 & 1.5 \\
Fish & 20.0 & 0.3 \\
Invertebrates & 51.0 & 6.5 \\
Carcasses & 49.0 & 25.3 \\
Plants & 89.0 & 18.8 \\
\hline
\end{tabular}


Although both species are omnivorous, the red fox is more dependent on the availability of voles than the raccoon dog is. At northern latitudes, eg in boreal Sweden, vole cycles have a strong effect on the litter size of the red fox (Englund 1970, Lindström 1989, 1992). The effect of voles on productivity is even greater because fewer females reproduce when voles are scarce than in the vole peak years (Lindström 1989). Vole cycles of 3 or 4 years occur also in southern Finland.

The litter size of the raccoon dog is only slightly affected by the abundance of voles: the mean litter size varies between 8 and 10 (Kauhala and Helle 1995). There is not much between-year variation in the proportion of reproducing females, either. Thus, when voles are scarce, raccoon dogs eat more eg shrews (which the red fox finds distasteful) and carcasses, vole cycles affect their productivity only slightly and they can invest relatively more in reproduction than the red fox.

\section{Winter dormancy}

For most animals, like the red fox, winter is the critical season at northern latitudes; in winter food is scarce, moving in snow consumes a lot of energy and low temperature increases energy consumption. However, raccoon dogs sleep during harsh winters and they are active only in mild weather. Thus, their energy demands in winter are low and they rely entirely on stored fat during winter. Consequently, raccoon dog females are in good condition still in March (the mating period) regardless of the weather and food availability during the winter, and they are able to invest heavily in reproduction. The mean weight of adult raccoon dog females in March is $5436 \mathrm{~g}(\mathrm{SD}=877, n=123)$ and in June $4585 \mathrm{~g}(\mathrm{SD}=1729$, $n=13)$ showing that there is on average $850 \mathrm{~g}$ ( $15.6 \%$ of body weight) extra fat in females in March.

In Japan raccoon dogs (subspecies $N$. p. viverrinus) are active also in winter and the litter size (determined from uterine scars) is commonly 4 or 5 (M. Kishimoto, pers. comm.) which also points to the conclusion that winter dormancy and large litters may be connected. In continental Asia, eg in SE parts of Russia where European raccoon dogs originate in, raccoon dogs sleep in winter and the mean litter size is 9 (Judin 1977).

If resources are abundant or females can rely on accumulated food reserves during breeding season the costs of reproduction can be low (Clutton-Brock 1991). Thus, extreme omnivory, the ability to accumulate large fat reserves and winter dormancy reduce the costs of reproduction by guaranteeing the good condition of raccoon dog females even in fluctuating environments.

\section{Susceptibility to predation}

The raccoon dog is short legged and clumsy and pups, in particular, are easy prey to other predators. Mortality during the first year of life was $87 \%$ in Finland (Helle and Kauhala 1993). If mortality rate of juveniles is high and if the litter size does not affect this mortality (caused eg by predation), natural selection will favour large litters. The red fox is more predaceous, it is much faster and even 
juveniles can escape other predators. According to Lindström (1989) juvenile mortality in Sweden is $39-56 \%$ during the first year of life. If the litters of the red fox were larger, eg starvation which probably is dependent on litter size might increase pup mortality. Thus, costs to the female would be greater, but the number of young surviving probably would not be higher. Consequently, natural selection would not favour so large litters, but the optimum litter size is smaller.

\section{Reproductive behaviour}

Reproductive behaviour, eg monogamy versus polygamy, may also affect pup survival and litter size. The raccoon dog is monogamous both in Finland (Kauhala et al. 1993b) and in the Far East (Judin 1977), and the male helps to rear the young (Ikeda 1983, Yamamoto 1987, Kauhala et al. 1993b). Raccoon dogs do not carry food to the den (because they eat only small food items), but the male is babysitting and the female is foraging to obtain enough food to lactate a large litter.

The social system of the red fox varies. The red fox may have a tendency to polygyny (von Schantz 1981). However, usually only one pair in each territory raises cubs (von Schantz 1981, Macdonald 1987, Lindström 1989) and the male carries food to the den (Macdonald 1987). The social system of the red fox in Finland, and the effect of the divison of labour between sexes on pup survival and litter size is a subject for future research.

Acknowledgements: I am very grateful to J. Elmberg and E. Helle for reading the manuscript and giving valuable comments on it. I also thank all hunters who sent me carcasses and R. Koivunen for helping to examine the carcasse material.

\section{References}

Bekoff M., Diamond J. and Mitton J. B. 1981. Life-history patterns and sociality in canids: Body size, reproduction, and behavior. Oecologia (Berl.) 50: 386-390.

Bekoff M., Daniels T. J. and Gittleman J. L. 1984. Life history pattern and the comparative social ecology of carnivores. Annual Review of Ecology and Systematic 15: 191-232.

Clutton-Brock T. H. 1991. The evolution of parental care. Princeton University Press, Princeton, New Jersey: 1-352.

Clutton-Brock T. H., Guinness F. E. and Albon S. D. 1982. Red deer. Behavior and ecology of two sexes. Edinburg University Press, Edinburg: 1-378.

Dietz J. M. 1984. Ecology and social organization of the maned wolf (Chrysocyon brachyurus). Smithsonian Contributions to Zoology 392: 1-51.

Eisenberg J. F. 1981. The mammalian radiations. An analysis of trends in evolution, adaptation, and behavior. The University of Chicago Press, Chicago: 1-610.

Englund J. 1970. Some aspects of reproduction and mortality rates in Swedish foxes (Vulpes vulpes), 1961-63 and 1966-69. Viltrevy (Swedish Wildlife) 8: 1-82.

Frame L. H., Malcolm J. R., Frame G. W. and van Lawick H. 1979. Social organization of African wild dogs (Lycaon pictus) on the Serengeti Plains, Tanzania 1967-1978. Zeitschrift für Tierpsychologie 50: $225-249$.

Helle E. and Kauhala K. 1993. Age structure, mortality and sex ratio of the raccoon dog in Finland. Journal of Mammalogy 74: 936-942.

Helle E. and Kauhala K. 1995. Reproduction of the raccoon dog in Finland. Journal of Mammalogy 76: 1036-1046. 
Helle P., Helle E., Lindén H. and Wikman M. 1994. [Snow track counts for wildlife triangles were carried out the sixth time - results of winter 1994]. Riistantutkimusosaston tiedote 133: 1-19. [In Finnish]

Ikeda H. 1983. Development of young and parental care of the raccoon dog Nyctereutes procyonoides viverrinus Temmick, in captivity. Journal of the Mammalogical Society of Japan 9: 229-235.

Judin V. G. 1977. [The raccoon dog of Primore and Priamure]. Nauka, Moscow: 1-150. [In Russian]

Kauhala K. 1992. Ecological characteristics of the raccoon dog in Finland. Ph D thesis, University of Helsinki, Helsinki: 1-19.

Kauhala K. 1993. Growth, size, and fat reserves of the raccoon dog in Finland. Acta Theriologica 38: 139-150.

Kauhala K. and Helle E. 1990. Age determination of the raccoon dog in Finland. Acta Theriologica 35: 321-329.

Kauhala K. and Helle E. 1993. Factors affecting the numbers of raccoon dog populations in Finland. Suomen Riista 39: 102-110. [In Finnish with English summary]

Kauhala K. and Helle E. 1995. Population ecology of the raccoon dog in southern Finland - a synthesis. Wildlife Biology 1: 3-9.

Kauhala K., Kaunisto M. and Helle E. 1993a. Diet of the raccoon dog, Nyctereutes procyonoides, in Finland. Zeitschrift für Säugetierkunde 58: 129-136.

Kauhala K., Helle E. and Taskinen K. 1993b. Home range of the raccoon dog (Nyctereutes procyonoides) in southern Finland. Journal of Zoology, London 231: 95-106.

Kleiman D. G. 1977. Monogamy in mammals. The Quarterly Review of Biology 52: 39-69.

Lampio T. 1953. [Studies of the diet of the red fox]. Suomen Riista 8: 156-164. [In Finnish]

Lavrov N. P. 1971. [The results of reintroductions of the raccoon dog (Nyctereutes procyonoides) in different provinces of the USSR]. Trudy kafedry biologii MGZPI 29: 101-160. [In Russian]

Lindström E. 1988. Reproductive effort in the red fox, Vulpes vulpes, and future supply of a fluctuating prey. Oikos 52: 115-119.

Lindström E. 1989. Food limitation and social regulation in a red fox population. Holarctic Ecology 12: $70-79$.

Lindström E. R. 1992. Diet and demographics of the red fox (Vulpes vulpes) in relation to population density - the sarcoptic mange event in Scandinavia. [In: Wildlife 2001: Populations. D. R. McCullough and R. H. Barrett, eds]. Elsevier Science Publishers Ltd, London: 922-931.

Lloyd H. G. 1980. The red fox. B. T. Batsford Ltd, London: 1-320.

Lloyd H. G., Jensen B., van Haaften J. L., Niewold F. J. J., Wandeler A., Bögeel K. and Arata A. A. 1976. Annual turnover of fox populations in Europe. Zentralblatt für Veterinärmedizin Reihe B: 23: 580-589.

Macdonald D. 1987. Running with the fox. Unwin Hyman, London: 1-224.

Moehlman P. D. 1986. Ecology of cooperation in canids. [In: Ecological aspects of social evolution, birds and mammals. D. I. Rubenstein and R. W. Wrangham, eds]. Princeton University Press, Princeton, New Jersey: 64-86.

Schantz T., von 1981. Female cooperation, male competition, and dispersal in the red fox Vulpes vulpes. Oikos 37: 63-68.

Storm G. L., Andrews R. D., Phillips R. L., Bishop R. A., Siniff D. B. and Tester J. R. 1976. Morphology, reproduction, dispersal, and mortality of Midwestern red fox populations. Wildlife Monographs 49: 1-82.

Tuomi J. 1980. Mammalian reproductive strategies: a generalized relation of litter size to body size. Oecologia (Berl.) 45: 39-44.

Western D. 1979. Size, life history and ecology in mammals. African Journal of Ecology 17: 185-204.

Yamamoto I. 1987. Male parental care in the raccoon dog Nyctereutes procyonoides during the early rearing period. [In: Animal societies: theories and facts. Y. Ito, J. L. Brown and J. Kikkawa, eds] Japan Scientific Societies Press, Tokyo: 189-195. 